\title{
Proceeding
}

10th INSHS International Christmas Sport Scientific Conference, 4-5 December 2015. International Network of Sport and Health

Science. Szombathely, Hungary

\section{Can the intensity of game load affect the shooting performance in basketball?}

\author{
TOMÁŠ VENCÚRIK
}

Faculty of Sports Studies, Masaryk University, Brno, Czech Republic

\begin{abstract}
Victory in a basketball game depends on many factors. One of the main factors that determine game performance of the team is the successfulness of basketball shooting. The aim of this study is to determine the influence of the game load intensity on basketball shooting performance. Ten senior female basketball players $\left(2^{\text {nd }}\right.$ division) participated in this study. Bleep test was used to set the maximal heart rate (HR $\left.\max \right)$ of each player. The intensity of game load was classified as follows: $<75,75-84,85-95,>95 \%$ of HR $\max$. During the two competitive games and the bleep test the HR was monitored by telemetric device. In the 1 st zone no field goal attempt was recorded. In the $2^{\text {nd }}$ zone the successfulness of shooting was $60 \%$, in the $3^{\text {rd }}$ zone $37.5 \%$ and in the $4^{\text {th }} z$ zone $45.2 \%$. The relation between the successfulness of shooting and the individual zones was statistically insignificant $\left(X^{2}=2.786 ; d f=2 ; p=0.24\right)$. Calculated Cramer's contingency coefficient $(V=0.149)$ shows weak strength of association. Based on the results we may conclude that the shooting performance in basketball game is not dependent on the intensity of game load. Besides the intensity of game load, the shooting performance can also be affected by many other factors. What is relevant for training process is that the $88.1 \%$ of all field goal attempts were made with $\mathrm{HR}$ over $85 \%$ of $\mathrm{HR}$ max. This fact should be taken into consideration by coaches when planning shooting practice sessions. Key words: HEART RATE, SUCCESSFULNESS OF SHOOTING, COMPETITIVE GAMES.
\end{abstract}

\footnotetext{
Corresponding author. Faculty of Sports Studies, Masaryk University, Brno, Czech Republic E-mail: vencurik@mail.muni.cz 10th INSHS International Christmas Sport Scientific Conference, 4-5 December 2015. International Network of Sport and Health Science. Szombathely, Hungary. JOURNAL OF HUMAN SPORT \& EXERCISE ISSN 1988-5202

(C) Faculty of Education. University of Alicante doi:10.14198/jhse.2016.11.Proc1.10
} 


\section{INTRODUCTION}

Victory in basketball depends on several factors and it is limited by the score, number of points, which the team reaches in comparison to the opponent. Only a successful shooting performance guarantees reaching enough points to win the game. All the other basketball skills assist in creating the most ideal position for successful completion of the offensive play. Gómez et al. (2008), Ibañez et al. (2009) a Lorenzo et al. (2010) point out the importance of successful 2-point field goal attempts as one of the performance indicators which are entered into the box score. These studies noticed a significant difference between the winning and losing teams based on the successful 2-point field goal attempts in male basketball-U16, U20 and senior categories.

Successfulness of basketball shooting may be influenced by several factors. Oudejans (2012) introduces a special visual training program as a factor increasing the successfulness of a 3-point shooting performance. The kinematic differences in shooting, which may influence its successfulness, among the individual player positions and different horizontal lengths were detected by Miller \& Bartlett (1996). Csataljay et al. (2013) monitor the impact of physical pressure of the defender on the successfulness of shooting under game conditions. Their findings confirm the common premise-the increasing degree of the defender's pressure had a significant influence on the decrease in percentage of the shooting successfulness and also on the victory in the game. Erčulj \& Supej (2009) document the impact of the increasing intensity of load on the kinematics of the shooting motion from the distance of $7.24 \mathrm{~m}$ (distance of a 3-point line in NBA). They state that, because of the high intensity of load and fatigue, significant changes in the release angles of the individual arm segments took place, what subsequently influenced the shooting successfulness from this distance. Therefore, they recommend to include more shooting drills performed in moderate up to high intensity of load and while fatigued.

To have a positive impact on the increase of the game performance one should have knowledge in physical and physiological demands of competitive games. Ben Abdelkrim et al. (2007) specifies these demands in the male U19 category and present the mean heart rate $(\mathrm{HR})$ during game at $91 \%$ of $H R_{\max }$, while significant differences between the mean HR of point guards and centers are detected. Scanlan et al. (2012) present a slightly lower value of the mean $\mathrm{HR}-82.4 \%$ of $\mathrm{HR}_{\max }$ - of female basketball players at a national level. Metthew \& Delextrat (2009), Ben Abdelkrim et al. (2010) and Vencúrik \& Nykodým (2015) give 80.4\% (senior female), $75.3 \%$ (U19 male) and $76.1 \%$ (senior female) share, respectively, of the total game time above $85 \%$ of HR max. The given studies present high physiological demands on basketball players, which means that also basketball skills will be performed in higher intensity and while fatigued. Therefore, the improvement of basketball skills in the training process should be based on gained information from the competitive games.

The aim of this study is to determine the influence of the intensity of load on the successfulness of basketball shooting in competitive games.

\section{MATERIAL AND METHODS}

\section{Participants}

Ten senior female basketball players (2nd division) participated in this study. Mean age of the players is 20.4 \pm 2.8 years, mean height $178.5 \pm 5.2 \mathrm{~cm}$, and mean weight $65.4 \pm 5.7 \mathrm{~kg}$. Players participated in $4-5$ training units per week and in this age category played 2 games every other week.

\section{Procedure}


Players completed the bleep test (Léger et al., 1988) in the given maximal heart rate. Based on the HR $\mathrm{max}_{\text {, }}$ the results are given in relative values (Ziv \& Lidor, 2009). Monitoring of HR and shooting successfulness was performed on 2 competitive games. Games were played under FIBA rules 2012/2013 and were recorded on camera Canon HG10 (Canon Inc., Tokyo, Japan). Dartfish TeamPro 6.0 software (Dartfish, Fribourg, Switzerland) was used for video-analysis of these games (O'Donoghue \& Holmes, 2015).

\section{Heart Rate}

HR was monitored with the use of telemetric system Suunto Team (Suunto Oy, Vantaa, Finland). The memory belts recorded HR every 2 seconds. System Suunto Team was synchronized with the beginning of the game. The intensity of load was assessed in 4 zones (table 1) Ben Abdelkrim et al., 2010). A mean value of HR (in interval $-2 s$ to $+8 s$ from the initial moment of shooting) was assigned to each field goal attempt because the intermittent nature of the physical activity and gained information-HR reacts on the increase of the intensity of load with a delay (Kenney et al., 2012). Based on the mean value of HR, individual zones of the intensity of load were assigned to each field goal attempt. The data of HR was processed via software Suunto Training Manager.

Table 1. Zones of the Intensity of Load Based on the Hrmax

\begin{tabular}{ccc}
\hline Zone & $\%$ z HRmax & Physiological demand \\
\hline 1 & $<75$ & Nízka \\
2 & $75-84$ & Stredná \\
3 & $85-95$ & Vysoká \\
4 & $>95$ & Maximálna \\
\hline
\end{tabular}

\section{Statistical Analysis}

The dependency of two categorical variables was expressed by two-dimensional contingency table $(2 \times 3)$ (O'Donoghue, 2012). The dependency of the shooting successfulness (made, missed) on the zone of the intensity of load (zones 2-4) -in which the field goal attempt was made-was observed. There was no field goal attempt in zone 1 (<75\% of HRmax), therefore it was not considered in the results. Chi-square $\left(X^{2}\right)$ test was used to determine the dependency between the observed variables. The strength of association between the variables was expressed by Cramer's contingency coefficient $(V)$. All statistical tests were carried out in software Statistica 12 (StatSoft Inc., Tulsa, USA). The level of statistical significance was set for $\alpha=5 \%$.

\section{RESULTS AND DISCUSSION}

There was no field goal attempt in the zone 1 in neither of the two games. In zone 2 were 15 field goal attempts from which 9 were made, it corresponds to $60 \%$ successfulness. In zone 3 were 80 field goal attempts, while 50 were missed and 30 made. The players were shooting in the $3^{\text {rd }}$ zone with the lowest successfulness of $37.5 \%$. In zone 4 (above $95 \%$ of HRmax) were 31 field goals and successfulness reached $45.16 \%$ (14 made and 17 missed field goal attempts) (table 2, fig. 1). In zone 2 were $11.9 \%$ of all field goal attempts. Zone 3 has the highest number of field goal attempts, what is $63.5 \%$ of all field goal attempts. In zone 4 , under the maximal intensity of load, the percentage of all field goal attempts was $24.6 \%$ (fig. 2). 
Table 2. Shooting in Indvidual Zones of the Intensity of Load

\begin{tabular}{lccc}
\hline & Zone 2 & Zone 3 & Zone 4 \\
\hline Made shots & 9 & 30 & 14 \\
Missed shots & 6 & 50 & 17 \\
Field goal attempts & 15 & 80 & 31 \\
\hline
\end{tabular}

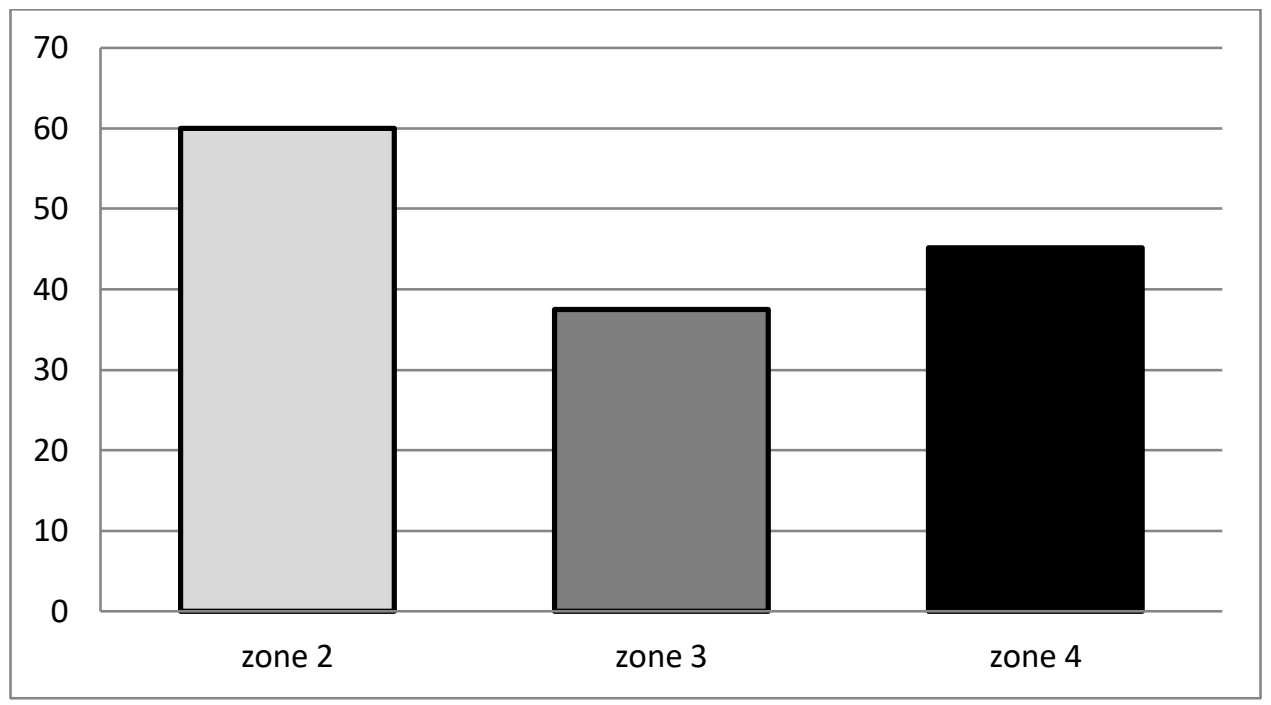

Figure 1. Percentage of Successfulness in the Individual Zones of the Intensity of Load

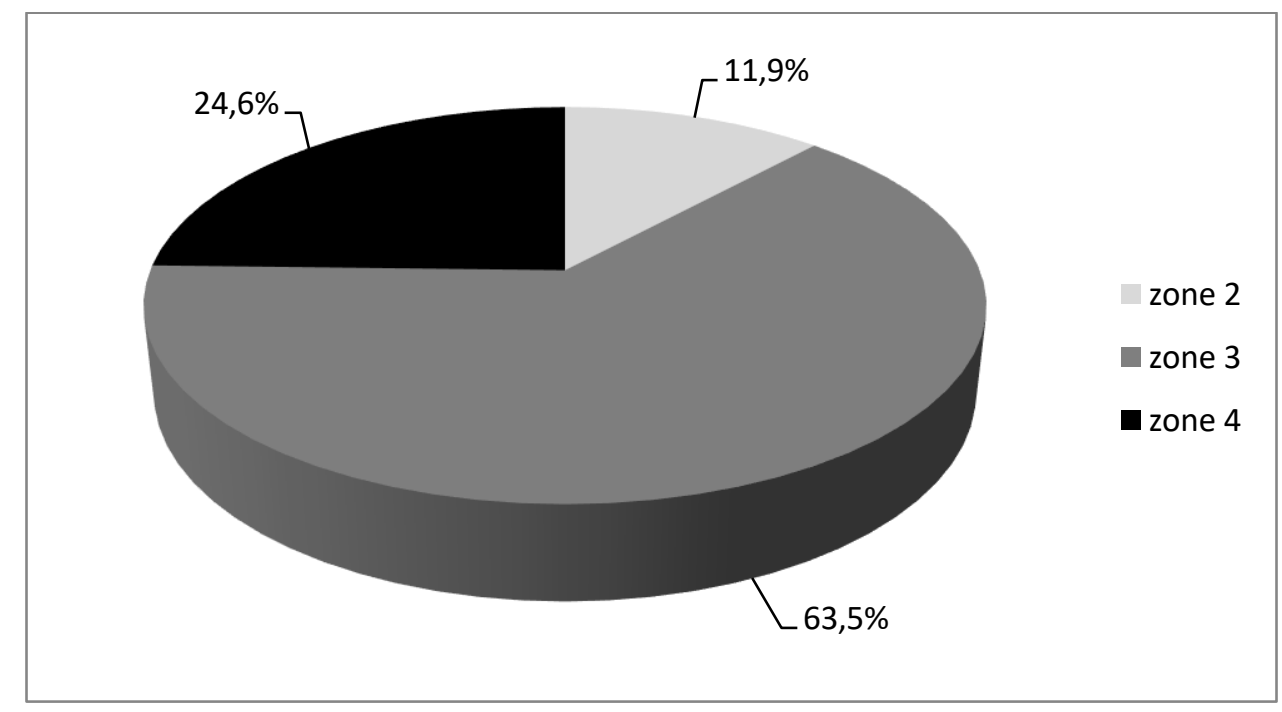

Figure 2. Percentage of Shooting in the Individual Zones of the Intensity of Load

The dependency between the successfulness of shooting in the individual zones of the intensity of load was not statistically significant $\left(X^{2}=2.786 ; \mathrm{df}=2 ; p=0.24\right)$. Calculated Cramer's coefficient ( $V=0.149$ ) demonstrates a weak dependency. Based on the results, it may be concluded that the shooting successfulness in a basketball game does not depend on the intensity of load, under which it is performed. Apart from the intensity of load, other factors may impact, most likely, the successfulness of shooting. Csataljay et al. (2013) state that a defensive pressure was a significant factor that affected the shooting 
successfulness and also the outcome of the game. Moreover, they found out that the winning teams had a higher shooting effectivity when compared to the losing teams.

Erčulj \& Supej (2009) researched the impact of the increasing intensity of load and fatigue in the kinematic parameters of shooting. Results of their study clearly demonstrate the differences in the shooting technique as a result of a moderate and, predominantly, heavy fatigue. The influence of the increasing intensity of load and fatigue on passing skills was noticed in the study by Lyons et al. (2006). Okazaki \& Rodacki (2012) point out the impact of the increasing horizontal distance from the basket to the height, angle and velocity of the ball release. The shooting successfulness decreased by the increasing distance from $59 \%(2.8 \mathrm{~m})$ to $37 \%$ $(6.4 \mathrm{~m})$. Even though the impact of the increasing intensity of load on the shooting successfulness was not confirmed in this study, for a training process should be crucial that $88.1 \%$ of all field goal attempts were performed in the intensity above $85 \%$ of $\mathrm{HR}_{\max }$. We recommend this fact, along Erčulj \& Supej (2009), to be taken into consideration by coaches when framing shooting and training programs.

Based on the given studies, it may be stated that the disruptive factors (intensity of load, defensive pressure, and distance from the basket) significantly lower the quality of shooting performance. However, a lack of these studies is that most of them evaluate the impact of the disruptive factors on the game performance under modelled or training conditions. Moreover, they present only a selection of the individual factors, while their impact should be researched in a complex form-their parallel impact on the game performance. From this point of view, it is necessary to ensure more researches which would document the impact of disruptive factors in natural game conditions and their imminent influence. This could be of great benefit for the development of the player's performance.

\section{CONCLUSIONS}

This study was aimed at determining the influence of the increasing intensity of load on the shooting successfulness in competitive games of female basketball players, in $2^{\text {nd }}$ division. The results did not confirm a statistically significant dependency between the monitored variables. $88.1 \%$ of all field goal attempts were performed in the intensity above $85 \%$ of $\mathrm{HR}_{\max }$ is being here considered an important fact. This finding should be taken into consideration by coaches while framing shooting and training programs. In similar studies (under game conditions) it is recommended to consider not only impact of one factor (intensity of load) but also other contextual factors (defensive pressure, distance from basket, time of possession, etc.). An analysis of hundreds, or even thousands, of field goal attempts of the highest possible number of players would be needed to draw generally applicable conclusions.

\section{ACKNOWLEDGEMENTS}

This publication was written at Masaryk University as part of the project "The Intensity of Physical Load during Competitive Games of Young Female Basketball Players II" number (MUNI/A/1290/2014) with the support of the Specific University Research Grant, as provided by the Ministry of Education, Youth and Sports of the Czech Republic in the year 2015.

\section{REFERENCES}

1. Abdelkrim, N.B., Castagna, C., Jabri, I., Battikh, T., Fazaa, S.E., \& Ati, J.E. (2010). Activity profile and physiological requirements of junior elite basketball players in relation to aerobic-anaerobic fitness. Journal of Strength and Conditioning Research, 24(9), 2330-2342. 
2. Abdelkrim, N.B., Fazaa, S.E., \& Ati, J.E. (2007). Time-motion analysis and physiological data of elite under-19-year-old basketball players during competition. British Journal of Sports Medicine, 41(2), 69-75.

3. Csataljay, G., James, N., Hughes, M., \& Dancs, H. (2013). Effects of defensive pressure on basketball shooting performance. In International Journal of Performance Analysis in Sport, 13(3), 594-601.

4. Erčulj, F., \& Supej, M. (2009). Impact of Fatigue on the Position of the Release Arm and Shoulder Girdle over a Longer Shooing Distance for an Elite Basketball Player. In Journal of Strength and Conditioning Research, 23(3), 1029-1036.

5. Goméz, M.A., Lorenzo, A., Sampaio, J., Ibáñez, S.J., \& Ortega, E. (2008). Game-Related Statistics that Discriminated Winning and Losing Teams from the Spanish Men's Professional Basketball Teams. In Collegium Antropologicum, 32(2), 451-456.

6. Ibáñez, S.J., García, J., Feu, S., Lorenzo, A., \& Sampaio, J. (2009). Effects of consecutive basketball games on the game-related statistics that discriminate winner and losing teams. In Journal of Sports Science and Medicine, 8(3), 458-462.

7. Kenney, W.L., Wilmore, J.H., \& Costill, D.L. (2012). Physiology of sport and exercise (5 $5^{\text {th }}$ ed.). Champaign, IL, USA: Human Kinetics.

8. Léger, L.A., Mercier, D., Gadoury, C., \& Lambert, J. (1988). The multistage 20 metre shuttle run test for aerobic fitness. Journal of Sports Sciences, 6, 93-101.

9. Lorenzo, A., Gómez, M.A., Ortega, E., Ibáñez, S.J., \& Sampaio, J. (2010). Game related statistics which discriminate between winning and losing under-16 male basketball games. In Journal of Sports Science and Medicine, 9(4), 664-668.

10. Lyons, M., Al-Nakeeb, Y., \& Nevill, A. (2006). The impact of moderate and high intensity total body fatigue on passing accuracy in expert and novice basketball players. Journal of Sports Science and Medicine, 5, 215-227.

11. Matthew, D., \& Delextrat, A. (2009). Heart rate, blood lactate concentration, and time-motion analysis of female basketball players during competition. Journal of Sports Sciences, 27(8), 813-821.

12. Miller, S., \& Bartlett, R. (1996). The relationship between basketball shooting kinematics, distance and playing position. In Journal of Sports Sciences, 14, 243-253.

13. O'Donoghue, P. (2012). Statistics for Sport and Exercise Studies. New York, NY, USA: Routledge.

14. O'Donoghue, P., \& Holmes, L. (2015). Data Analysis in Sport. New York, NY, USA: Routledge.

15. Okazaki, V.H.A., \& Rodacki, A.L.F. (2012). Increased distance of shooting on basketball jump shot. In Journal of Sports Science and Medicine, 11, 231-237.

16. Oudejans, R.R.D. (2012). Effects of Visual Control Training on the Shooting Performance of Elite Female Basketball Players. In International Journal of Sports Science \& Coaching, 7(3), 469-480.

17. Scanlan, A. T., Dascombe, B. J., Reaburn, P., \& Dalbo, V. J. (2012). The physiological and activity demands experienced by Australian female basketball players during competition. Journal of Science and Medicine in Sport, 15, 341-347.

18. Vencúrik, T., \& Nykodým, J. (2015). The Intensity of Load Experienced by Female Basketball Players during Competitive Games. In International Journal of Medical, Health, Biomedical, Bioengineering and Pharmaceutical Engineering, 9(7), 536-539.

19. Ziv, G., \& Lidor, R. (2009). Physical Attributes, Physiological Characteristics, On-Court Performances and Nutritional Strategies of Female and Male Basketball Players. Sports Medicine, 39(7), 547-568. 